many cases increases the diastatic action several fold. That the albumin is an essential factor in diastatic action could not be positively proved, but the results of further experience have tended to strengthen this belief. Of all the preparations that we have made, none from which albumin was absent showed amylolytic power, and those containing the most albumin were the most active. It was always possible to roughly judge of the diastatic power of a preparation, by heating a portion of its solution to $65^{\circ} \mathrm{C}$. and observing the a mount of coagulum formed.

The fact that active diastase was obtained only from solutions whose alcohol content lies between fifty and sixty per cent., may, we think, be regarded as probable evidence that the enzyme is not something carried down mechanically with the proteid.

\title{
THE PROTEIDS OF MALT.
}

By Thomas B. OsBor Ne and George F. Camprelt.

Received May 15,1896 .

$A^{\mathrm{s}}$ is well known, water extracts a considerable quantity of of at least five distinct bodies, namely, a globulin, an albumin and three proteoses. Whether true peptones are present was not determined, for the malt extracts are so strongly colored that the biuret test entirely fails. Besides the proteids soluble in water another exists that may be taken up by dilute alcohol (of 0.9 sp. gr.). After extracting malt with saline solutions and alcohol, a further quantity of proteid matter remains, the nature of which we have not been able to determine.

Malt-Globulin.-Ten kilograms of air-dried malt, freshly prepared by ourselves in the laboratory, and ground to a fine meal were treated with twenty liters of water and, after standing three hours, were squeezed out in a press and the solution filtered clear. The residual meal was treated with eight liters more of water and the second solution was pressed out and filtered. The united solutions were saturated with ammonium sulphate, the precipitate was suspended in about four liters of water and dialyzed for three days, when it dissolved, with the exception of a

1 From the Report of the Connecticut Agricultural Experiment Station for 1895 . Communicated by the authors. 
slight residue. In order to reduce its volume and separate impurities, the filtered solution was again saturated with amımonium sulphate, the precipitated substance was suspended in 1500 cubic centimeters of water and dialyzed until the greater part of the ammonium sulphate had been removed, when the solution was filtered clear. The matters now remaining undissolved were treated with ten per cent. salt solution to extract any soluble globulin which might have been deposited during dialysis, and the substance not taken up in salt-solution was filtered out. This last unquestionably consisted almost entirely of insoluble globulin, but as it separated from an unfiltered solution and was small in quantity it was not further examined. The salt-solution was then dialyzed free from chlorides, and the globulin thus precipitated was filtered out, washed with alcohol and dried over sulphuric acid. But 0.5 gram of substance was obtained which, dried at $\mathrm{I} 1 \mathrm{O}^{\circ}$, gave 0.93 per cent. of ash and, reckoned ash-free, I5.70 per cent. of nitrogen. This was marked preparation I.

The solution of the ammonium sulphate precipitate, containing the bulk of the malt-proteid, from which the insoluble matter yielding preparation I had been filtered, was dialyzed, first, into water, until the salts were mostly removed, and then into an equal volume of alcohol of $0.84 \mathrm{sp}$. gr. for forty-eight hours. The proteid thus precipitated was filtered out and the filtrate was dialyzed into alcohol. After filtering out the second precipitate, the filtrate was dialyzed into stronger alcohol, and this process was repeated, thus depositing the proteids in four fractions, a fifth being obtained by adding absolute alcohol to the remaining solution as long as anything was thrown down. Each of these five fractions was then treated with water to dissolve albumins and proteoses and the resulting solutions were dialyzed in water for several days. The first four fractions were but partly soluble in water, and accordingly, the insoluble parts, after washing with water, were treated with ten per cent. sodium chloride solution, and the portion which in each case remained undissolved was filtered out, washed thoroughly with water and alcohol and dried at $110^{\circ}$ for analysis. The four saline extracts were then dialyzed, bnt those from the third and fourth fractions were 
found to contain only trifling quantities of proteids. That from the second fraction gave no precipitate of globulin on dialysis, but by adding alcohol to the solution 0.49 gram of preparation 2 was obtained, having 4.33 per cent, of ash and, calculated ashfree, 15.I 8 per cent. of nitrogen. The sodium chloride extract from the first fraction gave a precipitate on dialysis which, after washing with water and with alcohol, weighed one and twotenths grams, 3 .

The filtrate from 3 , by precipitation with alcohol, vielded 4 , weighing I.54 grams.

After extracting the four fractional precipitates with water and with salt solution, the undissolved residue, in each case, was washed thoroughly with salt solution, with water and with alcohol and dried over sulphuric acid, giving, in the order named, preparation 5 weighing eight grams, 6 weighing five grams, 7 weighing 2.87 grams, and 8 weighing nine-tenths gram. These preparations, dried at $\mathrm{I}_{10} 0^{\circ}$, had the following composition:

MaIt-Globlim, BYNeDESTiN.

\begin{tabular}{|c|c|c|c|c|c|c|c|}
\hline & 3. & 4 & \multirow{6}{*}{ I 5.87} & 5 & 6. & 7 & 8. \\
\hline Carbon.... & $53 . \mathrm{II}$ & 53.58 & & 53.55 & $53.5 I$ & 53.25 & 53.42 \\
\hline Hydrogen. & 6.45 & 6.70 & & 7.01 & 6.75 & $\cdots$ & 7.15 \\
\hline Nitrogen.. & I 5.78 & $1,5.86$ & & $I_{5} \cdot 72$ & I 5.87 & 16.12 & 16.65 \\
\hline Sulphur , & \multirow{2}{*}{24.66} & \multirow{2}{*}{23.86} & & I. 23 & I. 12 & I. 38 & $>22.78$ \\
\hline Oxygen $\}$ & & & & 22.49 & 22.75 & & \\
\hline & 100.00 & 100.00 & & 100.00 & & & 100.00 \\
\hline Ash. & 0.75 & I.43 & & 1.09 & 0.66 & 0.55 & 0.24 \\
\hline
\end{tabular}

Preparations 5 and 6 have the same composition as the globulin 3 and 4 obtained from the sodium chloride extracts of the fractional precipitates, while $S$ contains nearly one per cent. more nitrogen, and as will be seen later, has nearly the same composition as malt albumin and is unquestionably for the most part albumin coagulated by the action of the alcohol. 7 appears to be a mixture of coagulated globulin and albumin. In a similar manner three other preparations of the coagulated globulin 9 , Io and I were obtained from another lot of malt. 
MALT-GIOBULIN, BYNEDESTIN.

\begin{tabular}{|c|c|c|c|}
\hline & 9 & Io & 11 \\
\hline Carbon...$\ldots \ldots \ldots$ & 52.90 & 52.99 & 53.15 \\
\hline Hydrogen......$\ldots$. & 6.74 & 6.64 & 6.52 \\
\hline Nitrogen.............. & $55 \cdot 33$ & I5.3I & I5.8I \\
\hline Sulphur $\ldots \ldots \ldots \ldots \ldots$ & I.I7 $\}$ & 25.06 & $\{1.47$ \\
\hline Oxygen $\ldots \ldots \ldots \ldots$ & $23.86 S$ & & 23.05 \\
\hline & 100.00 & 100.00 & I00.00 \\
\hline Ash $\ldots \ldots \ldots \ldots \ldots$ & 0.44 & 0.32 & 0.23 \\
\hline
\end{tabular}

Preparations 9 and ro are lower in carbon and nitrogen than those just described, probably because, having been prepared in a smaller quantity, they carried down a larger proportion of impurities when thrown out of solution by alcohol.

From a mait extract that had been concentrated in vacuo at a low temperature, for which we are indebted to Mr. C. von Egloffstein, alcohol, added to make forty-six per cent. by weight of the mixture, threw down a large quantity of coagulated globulin that was not further examined, the filtrate from which, on increasing the content of alcohol to sixty per cent., gave a second precipitate that was largely soluble in water. It was accordingly mixed with water and with ammonium sulphate in excess, and the substance thus thrown down was suspended in a liter of water and dialyzed for five days. The insoluble residue in the dialyzer, when washed with water and alcohol, gave preparation I2, weighing 26.78 grams. From this same extract by fractional precipitation with alcohol another small preparation of coagulated globulin, I3, was obtained.

Summary of ANalyses of Malt-Globulin, Bynedestin.

\begin{tabular}{|c|c|c|c|c|c|c|}
\hline & I & 2 & 3 & 4 & 5 & 6 \\
\hline Carbon ....... & & & $53 . \mathrm{II}$ & $53 \cdot 5^{8}$ & 53.55 & $53.5 \mathrm{I}$ \\
\hline Hydrogen ... & & & 6.45 & 6.70 & 7.01 & 6.75 \\
\hline Nitrogen .... & 15.70 & $\mathrm{I} 5 . \mathrm{I} 8$ & 15.78 & 15.86 & $15 \cdot 72$ & I 5.87 \\
\hline Sulphur $\left\{\begin{array}{l}\ldots \\
\ldots\end{array}\right.$ & & & 24.66 & 23.86 & 1.23 & I.I 2 \\
\hline Oxygen $) \ldots$ & & & & & 22.49 & 22.75 \\
\hline & & & 100.00 & 100.00 & $100 . \infty$ & $100 . \infty$ \\
\hline
\end{tabular}


546 THOMAS B. OSBORNE AND GEORGE F. CAMPBELI.

\begin{tabular}{|c|c|c|c|c|c|}
\hline & 9 & IO & II & 12 & 13 \\
\hline Carbon ....... & 52.90 & 52.99 & 53.15 & 53.04 & 52.96 \\
\hline Hydrogen ... & 6.74 & 6.64 & 6.52 & 6.57 & 6.83 \\
\hline Nitrogen .... & I 5.33 & $\mathrm{I}_{5} \cdot 3 \mathrm{I}$ & $15.8 \mathrm{I}$ & I 5.94 & I 5.96 \\
\hline Sulphur $\left\{\begin{array}{l}\ldots \\
\ldots\end{array}\right.$ & I.I 7 & 25.06 & 1.47 & & \\
\hline Oxygen $\ldots$ & 23.86 & & 23.05 & $23.6 \mathrm{I}$ & 24.25 \\
\hline & 100.00 & 00.00 & 100.00 & I 00.00 & 100.00 \\
\hline
\end{tabular}

Although considerable differences exist among these analyses, they agree with each other as well perhaps as could be expected considering the difficulty of preparing the substance in a state of purity.

Whether other globulins occurred in the malt could not be determined by fractional precipitation owing to the small total quantity of globulin present.

The malt residue remaining after extracting with water, in the case first described, was treated with ten per cent. salt solution and the clear filtered liquid was dialyzed until free from chlorides. The precipitated globulin was filtered out, washed with water and alcohol and dried nver sulphuric acid. This preparation, I4, weighed 4 . I 2 grams and had the following composition :

MALT-GLobULiN, BYNEDESTIN.

\begin{tabular}{|c|c|c|}
\hline I. & $\begin{array}{l}14 \\
\text { II. }\end{array}$ & Average \\
\hline Carbon ............ $55^{2.94}$ & 52.78 & 52.86 \\
\hline Hydrogen $\ldots \ldots \ldots \ldots \ldots 6.87$ & 6.79 & 6.83 \\
\hline Nitrogen..$\ldots \ldots \ldots \ldots$ I6.I6 & I6.18 & 16.17 \\
\hline Sulphur ............ I.I4 & & I. I4 \\
\hline Oxygen..$\ldots \ldots \ldots \ldots$ & & 23.00 \\
\hline & & 100.00 \\
\hline
\end{tabular}

It is to be noted that the carbon is a little lower and the nitrogen higher than the average of the figures previously obtained. This is perhaps due to presence of a little edestin, ' the globulin of ungerminated barley. Edestin is not readily soluble in dilute saline solutions, such as are formed on treating seeds with water, and, if occurring in the malt, ought to be present in the salt extract of the meal after it has been exhausted with water.

1 Annual Report of Conn. Agr. Expt. Station for 1894, p. 172, and Journal of Ameri. can Chemical Society, 17,545 . 
Owing to the incomplete extraction with water, the preparation obtained in this case should be a mixture of the two globulins, if both are present. Edestin can only occur in extremely small quantity in malt, since but 4. I 2 grams of globulin were obtained by extracting ten kilograms of malt with salt solution after treatment with water, and most of this consisted of the more soluble globulin first described. It is interesting to note the practically complete disappearance of edestin during germination and the formation of the more soluble globulin with three per cent. less nitrogen and two per cent. more carbon. It is, of course, not demonstrated that the malt globulin is derived from edestin, but that the proteids undergo extensive changes before conversion into proteoses and peptones is very evident.

When dissolved in considerable quantity in salt solution, bynedestin is precipitated by water, is not precipitated by saturation with sodium chloride, and but partly by saturation with magnesium sulphate. With the biuret test it gives a violet color. Dissolved in ten per cent. sodium chloride solution and heated to $65^{\circ}$, a turbidity is produced which increases to flocks at $84^{\circ}$. The coagulum gradually augments as the temperature rises but, after heating to $100^{\circ}$, the filtrate from the coagulum yields an abundant precipitate on adding dilute hydrochloric acid. The solution in ten per cent. sodium chloride brine gives a precipitate with acetic acid which is soluble in an excess of the acid. These reactions show that this body is in no sense a proteose, but has characters common to plant globulins. Bynedestin formed about sixty per cent. of the total water-soluble proteid matter in the malt extract first described in this paper. Out of a total of 33.27 gram of proteid recovered in the different preparations from 10,000 grams of malt, 19.88 grams consisted of bynedestin.

Malt Albumin, Leucosin.-Under the name leucosin, one of us has described an albumin occurring in small quantity in the seeds of wheat, rye and barley. In the aqueous malt-extracts an albumin is found identical wlth leucosin in properties and composition. As stated in previous papers, this albumin is so intimately associated with diastatic action as to make probable that it is either diastase itself or an essential factor in diastatic 
amylolysis. In attempts to fractionally separate malt-leucosin from the associated proteids, many preparations have been made which are mixtures of leucosin with proteose. In several cases these mixtures have been analyzed and have so nearly the composition of leucosin as to make certain that one of the proteoses of malt has very nearly the same ultimate composition as the albumin. Analyses of these mixtures may therefore be taken to represent the composition of either of these proteids.

In the extraction first described in this paper, two preparations, 15 and 16 , of albumin coagulated by alcohol, were obtained from solutions out of which the globulin had been precipitated by alcohol. If, as is invariably assumed, proteose cannot be rendered insoluble by contact with alcohol, these preparations may be taken to represent the composition of malt albumin. Their composition is here compared with that of leucosin coagulated by heat.

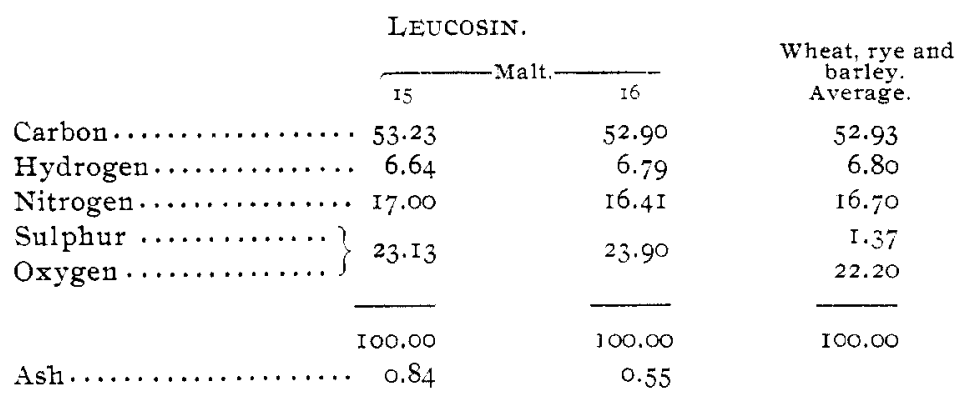

The following figures give the composition of preparations derived from three different samples of malt. These were all obtained by precipitating the proteids with ammonium sulphate, dissolving the precipitates in water, dialyzing away the greater part of the salt and fractionally precipitating the solutions with alcohol. The fractions were dissolved in water as far as possible, filtered from the undissolved globulin and the aqueous solutions dialyzed for several days in water and then in alcohol. The proteids thus precipitated were mixtures of proteose and albumin. It will be noted that they all agree fairly well with one another and with leucosin in composition. Since these mixtures contained 
from six and a half to fifty per cent. of albumin, it is evident that the two proteids have a very similar composition.

Malt leucosin and Proteose.

\begin{tabular}{|c|c|c|c|c|c|c|c|c|}
\hline & 17 & I8 & I9 & 20 & 21 & 22 & 23 & 24 \\
\hline Carbon................ & 53.16 & 53.19 & 52.80 & 52.50 & $5^{2 .} \cdot 3^{8}$ & 52.85 & $52.6 \mathrm{I}$ & 52.55 \\
\hline Hydrogen $\ldots . .$. & 7.03 & $6.7 \mathrm{I}$ & 6.96 & 6.72 & 6.63 & 6.67 & & \\
\hline Nitrogen......... & 16.50 & 16.60 & 16.09 & I6. 10 & I6.5I & I6.25 & I6.35 & I6.4I \\
\hline Sulphur $\ldots . .$. . & 23.31 & I.38 & I. 45 & 24.68 & 24.48 & 24.23 & & \\
\hline Oxygen $\ldots . .$. ' & & 22.12 & 22.70 & & & & & \\
\hline & 0.00 & $\infty 0.00$ & 00.00 & 00.00 & 100.00 & 100.00 & & \\
\hline $\mathrm{ch}$ & 0.84 & $0.7^{8}$ & 0.59 & 0.66 & I. 55 & 0.22 & 0.51 & \\
\hline
\end{tabular}

The preparations containing the most albumin, when dissolved in water, became turbid on heating to $50^{\circ}$ and formed flocculent coagula at $58^{\circ}$. By saturating their solutions with magnesium sulphate the albumin was completely thrown out, and together with it much of the proteose. Saturating solutions of these preparations with sodium chloride, gave no precipitate when they contained but little albumin, but a heavy precipitate appeared on adding acetic acid to the salt-saturated solution. Solutions of the preparations containing much albumin gave precipitates on saturating with sodium chloride.

PROTEOSES OF MALT.

The proteose associated with albumin has the properties of a protoproteose, since it is readily and abundantly precipitated from its salt-saturated solution on adding acetic acid.

When malt extract is fractionally precipitated with alcohol a considerable quantity of proteose is thrown down before the albumin, so that the water-soluble part of the first fraction is chiefly proteose. The proportion of albumin in the precipitates increases as the alcohol is made stronger up to the point where it is all precipitated. At this stage much proteose remains dissolved which behaves differently from that first thrown down. A large quantity of concentrated malt extract was precipitated by alcohol added to 60 per cent., and after filtering, the proportion of alcohol was raised to seventy-two per cent. The substance thereby precipitated, when dried over sulphuric acid, weighed thirty-eight grams. This was dissolved in water, the solution was heated to boiling, 
the coagulated albumin was filtered out and twenty per cent. of sodium chloride added to the solution. This caused a slight precipitate which was evidently the alcohol-soluble proteid, to be described later. The filtrate from this substance was then treated with a little acetic acid, which produced a copious precipitate that was filtered out and dissolved in water. This solution, exactly neutralized with sodium carbonate and fully saturated with salt, yielded a considerable precipitate, which was filtered out, dissolved in water and dialyzed free from chlorides.

A very small deposit, consisting of minute spheroids, was found in the dialyzer. This dissolved readily in exceedingly dilute salt solution, from which it was thrown down by much water. On adding nitric acid to the solution of this substance a precipiate was produced that dissolved on warming and reappeared on cooling, gave a clear pink biuret reaction and was precipitated by copper sulphate. On boiling its solution not even a turbidity was produced. Except for its behavior on heating, this substance has all the reactions of a heteroproteose. The amount obtained was exceedingly small, only enough for the above reactions. The solution filtered from this heteroproteose was concentrated by gently boiling over a low flame.

During concentration of the solution filtered from the heteroproteose a coagulum developed as a film on the surface of the liquid and sides of the dish. We have frequently noticed that plant proteoses from various seeds coagulate in this manner although behaving in most other respects like typical proteose. This coagulum, 25, filtered out washed with water and alcohol and dried over sulphuric acid, weighed 0.29 gram and contained I6.84 per cent. of nitrogen.

The filtrate from 25 was precipitated by alcohol and gave I.45 gram of 26 , having the following composition, when dried at $110^{\circ}$ :

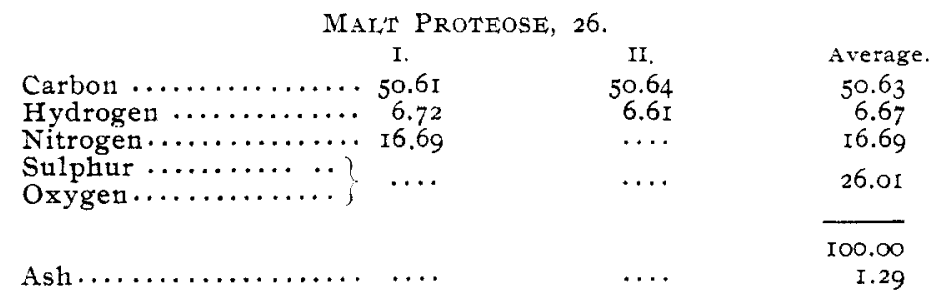


As will be remembered, in making these preparations, 25 and 26 , the proteose was precipitated, first, by adding acetic acid to the solution containing twenty per cent. of salt and, second, by dissolving the precipitate thus produced in water and saturating the neutralized solution with salt. The filtrate, A, from the first, as well as the filtrate, $B$, from the second precipitation, still contained proteose.

A was therefore neutralized with sodium carbonate and saturated with salt, but, as no precipitate resulted, acetic acid was added as long as any proteid was thrown down.

$B$ was treated similarly with acetic acid and the two precipitates thus obtained from the salt-saturated solutions were collected on the same paper and the filtrates were united and marked C. The precipitates were dissolved in water, the solution carefully neutralized, dialyzed free from chlorides and then concentrated by slow boiling. During concentration a small coagulum separated which was filtered out, washed with water and alcohol and dried over sulphuric acid. This preparation, 27, weighed 0.22 gram and contained, without correcting for ash, 16.40 per cent. of nitrogen.

An excess of alcohol was added to the filtrate from 27 , and the precipitate produced, after treating in the usual manner, gave I. 49 gram of preparation 28 , which, dried at I $10^{\circ}$, had the following composition :

\begin{tabular}{|c|c|c|}
\hline \multicolumn{3}{|c|}{ MALT PROTEOSE, 28.} \\
\hline I. & II. & Average \\
\hline Carbon $. \ldots \ldots \ldots \ldots \ldots, 49.82$ & 49.87 & 49.85 \\
\hline Hydrogen $\ldots \ldots \ldots \ldots \ldots \ldots .6 .69$ & 6.64 & 6.67 \\
\hline Nitrogen.$\ldots \ldots \ldots \ldots \ldots$ 16.00 & $\ldots$ & 16.00 \\
\hline Sulphur $\ldots \ldots \ldots \ldots \ldots, \quad \ldots$ & & 27.48 \\
\hline Oxygen $\ldots \ldots \ldots \ldots \ldots, \ldots$ & $\cdots$ & \\
\hline & & 100.00 \\
\hline $\operatorname{Ash} \ldots \ldots \ldots \ldots \ldots \ldots \ldots \ldots$ & $\ldots$ & I. 54 \\
\hline
\end{tabular}

The salt-saturated filtrate, $\mathrm{C}$ from which 27 and 28 had been precipitated, was neutralized and dialyzed until much of the salt had been removed, then concentrated and dialyzed until free from chloride. The solution was finally concentrated to small volume and precipitated with alcohol. The substance so 
obtained, after treating as usual, weighed 6.25 grams but was found to contain 4.70 per cent. of ash and only $8.9 \mathrm{I}$ per cent. of nitrogen, reckoned ash-free. This precipitate, which was expected to contain deuteroproteose, evidently included much nonproteid matter.

It will be noticed that of the thirty-eight grams of substance taken, only a very small part was recovered. It is probable that a large share of the substance (p. 550) was non-proteid, and also that during the dialysis much proteose was lost by diffusion.

Preparation 26 has the properties of a protoproteose and may be regarded as such. Preparation 28 is a mixture of proto- and deuteroproteose. Pure deuteroproteose was not obtained, it having been impossible to separate the non-proteid substances associated with it.

It thus appears that at least two protoproteoses exist in mait, for 26 has much less carbon than the mixtures of proteose and albumin, I 7 to 24 . Preparation 17 contains about ninety-five per cent. of proteose and has 53.16 per cent. of carbon, whereas 26 has only 50.63 per cent. of carbon. This difference can scarcely be due to non-proteid impurities, for 26 contains even more nitrogen than I7. According to the definitions now accepted, a protoproteose is any form of proteid which is soluble in pure water, uncoagulable by heat, precipitable by saturation with sodium chloride, and gives a pink biuret reaction and a precipitate with nitric acid that dissolves on warming and reappears on cooling. The protoproteoses obtained by artificial digestion, usually have a composition varying with that of the proteids from which they are derived, and the proteoses of malt may also be expected to differ according as they originate from one or another of the several proteids of barley. While the plant proteoses resemble the digestive proteoses in the reactions just specified, some of their physical properties are so different that it is not improbable that they are quite distinct substances.

MALT PROTEID SOLUBLE IN DILUTE ALCOHOL. BYNIN.

Three kilograms of ground malt were extracted with alcohol of $0.90 \mathrm{sp.} \mathrm{gr.} \mathrm{The} \mathrm{extract} \mathrm{was} \mathrm{filtered} \mathrm{clear,} \mathrm{and} \mathrm{concen-}$ trated to about one-third its original volume, on a water bath. 
When cool the solution was poured off from the separated proteid and the latter was washed with dilute salt solution, with water, with ether to remove adhering water, and finally with absolute alcohol. Dried over sulphuric acid, this preparation, 29, weighed 33. I grams, being I. I I per cent. of the malt.

Dried at $110^{\circ}$ it had the following composition:

ByNIN, 29.

$$
\text { I. }
$$

Carbon $\ldots \ldots \ldots \ldots \ldots \ldots+55.01$

Hydrogen........... 6.77

Nitrogen............. 15.98

Sulphur ............ 0.94

Oxygen $\ldots \ldots \ldots \ldots \ldots \ldots \ldots$

Ash $\ldots \ldots \ldots \ldots \ldots \ldots \ldots \ldots$

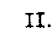

54.93

6.49

I6. 13

-...

$\cdots$

...

$$
\begin{gathered}
\text { Average. } \\
54.97 \\
6.63 \\
16.06 \\
0.94 \\
21.40 \\
\hline 100.00 \\
0.67
\end{gathered}
$$

In order to fraction this stbstance, twenty-seven grams were dissolved in alcohol of $0.70 \mathrm{sp}$. gr., the solution filtered perfectly clear, concentrated to small, volume and poured into absolute alcohol, a few drops of ten per cent. salt solution being added to cause the proteid to separate. The precipitate so produced was filtered out, treated with absolute alcohol and dried over sulphuric acid. This preparation, 30, weighed twenty grams, and when dried at $I 10^{\circ}$ had the following composition:

ByNIN, 30.

I.

Carbon $\ldots \ldots \ldots \ldots \ldots, 54.74$

Hydrogen ........... 6.6I

Nitrogen............ I6.2I

Sulphur ............. 0.83

Oxygen..................

II.

55.08

6.62

Average.

54.91

I 6.06

6.62

$\ldots$

16.14

$\cdots$

0.83

55.07

100.00

Ash $\ldots \ldots \ldots \ldots \ldots \ldots \ldots \ldots \ldots$

0.40

Of preparation 30 , sixteen grams were dissolved in $\mathrm{I} 80 \mathrm{cc}$. of warm alcohol of fifty per cent. by volume, and a part of the proteid precipitated by cooling to $0^{\circ} \mathrm{C}$. The solution was decanted and the precipitate, $30 a$, was treated as just described for 30 . The substance now separated, $30 b$, was treated in the same manner. 30c, thus obtained, was dissolved in a little strong 
alcohol and the perfectly clear solution poured into absolute alcohol, adding also a few drops of ten per cent. salt solution. The precipitate was then dehydrated with absolute alcohol and dried over sulphuric acid. This preparation, $3 \mathrm{I}$, weighed eight and three-tenths grams and gave the following results on analysis :

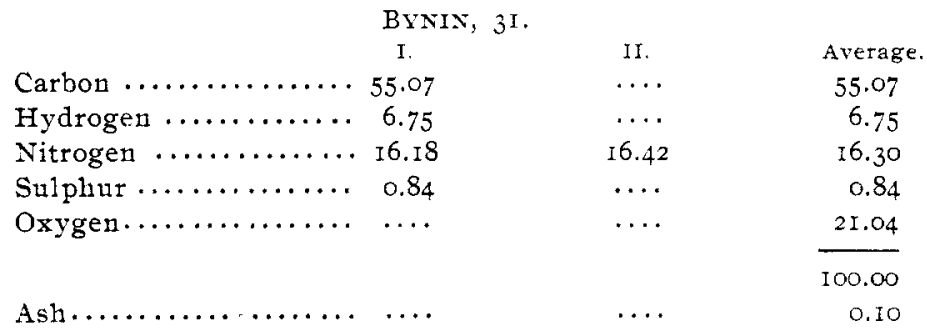

The solutions containing fifty per cent. of alcohol, which had been decanted from $30 a, 30 b$ and $30 c$ were united, concentrated to small volume, cooled, and the liquid poured off from deposited substance. The latter, dehydrated with absolute alcohol and dried over sulphuric acid-preparation 32-weighed five grams.

As seen from the following table, these analyses show that the proteid has not been separated into fractions of differing composition.

\begin{tabular}{|c|c|c|c|c|c|}
\hline SUMMAR & $Y O F$ & ALYSIS & OF BYNIN & & \\
\hline & 29. & 30 & $3 \mathrm{I}$. & 32. & Average. \\
\hline Carbon $\ldots \ldots \ldots \ldots$ & 54.67 & $54.9 I$ & 55.07 & 55.16 & 55.03 \\
\hline Hydrogen $\ldots . . . \ldots$ & 6.63 & 6.62 & 6.75 & 6.67 & 6.67 \\
\hline Nitrogen $\ldots . \ldots \ldots \ldots$ & I6.06 & I6. 14 & I $6.3^{\circ}$ & 16.53 & $I 6.26$ \\
\hline 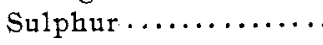 & 0.94 & 0.83 & 0.84 & 0.76 & 0.84 \\
\hline Oxygen $\ldots \ldots \ldots \ldots$ & 21.40 & 21.50 & 21.04 & 20.88 & $2 I .20$ \\
\hline & 00.00 & 100.00 & 100.00 & 100.00 & 100.00 \\
\hline Ash $\ldots \ldots \ldots \ldots \ldots \ldots$ & 0.67 & 0.40 & 0.10 & 0.16 & \\
\hline
\end{tabular}

These figures are, except for hydrogen, in remarkably close agreement with those given by Chittenden and Osborne for the composition of zein, the alcohol soluble proteid of maize ; but in properties the two bodies are very distinctly different. Compared with hordein, the alcohol soluble porteid of barley, this malt proteid contains about one per cent. more carbon and one per cent. less nitrogen. 
Alcohol Soluble Proteits.

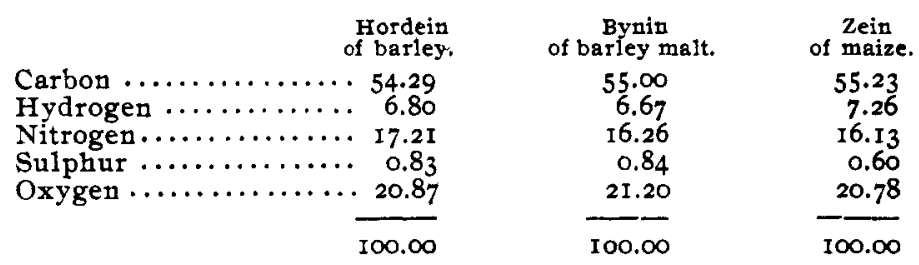

MALT PROTEID INSOLUBLE IN WATER SOLUTION AND DILUTE ALCOHOL.

The proteid remaining undissolved, after extracting malt with water, salt solution and alcohol, was not separated or identified, but its presence in considerable quantity was shown, as follows :

After extracting Ioo grams of malt first, with ten per cent. sodium chloride solution, and then with alcohol of $0.90 \mathrm{sp}$. gr., dehydrating with absolute alcohol and drying in the air, a residue was obtained which weighed seventy-five grams and contained 0.82 per cent of nitrogen, equivalent to 0.62 per cent. reckoned on the original malt. Assuming, as is probably true, that this nitrogen belongs to proteid matter, we have in the residue three and eight-tenths per cent. of proteid, insoluble in the reagents named.

\section{SUMMARY.}

In the malt used in this investigation we have found :

I. Bynedestin, readily soluble in very dilute salt solution, therefore largely passing into the aqueous extracts because of the soluble salts of the seed. This globulin contains two per cent. more carbon and three per cent. less nitrogen than edestin, the globulin of barley, and is much more soluble in very dilute salt solutions than edestin.

The composition of this globulin, as shown by the average of eleven analyses, is :

BYNEDESTIN.

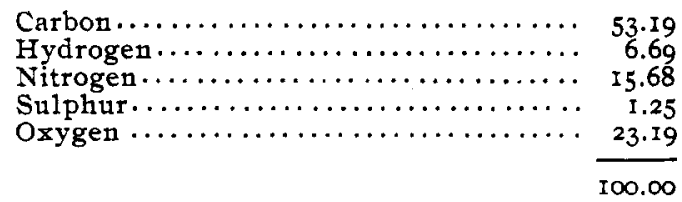


Bynedestin, dissolved in ten per cent. sodium chloride solution, gives a turbidity at $65^{\circ}$ and a flocculent coagulum at $84^{\circ}$, but, even after heating for some time at $100^{\circ}$, the coagulation is far from complete.

This proteid is not precipitated by saturating its solutions with sodium chloride, and but partly precipitated by saturating with magnesium sulphate.

2. Leucosin, an albumin, identical in composition and properties with the leucosin found in wheat, rye and barley. The composition of this proteid was found to be :

Malt Albumin, LeUcosin.

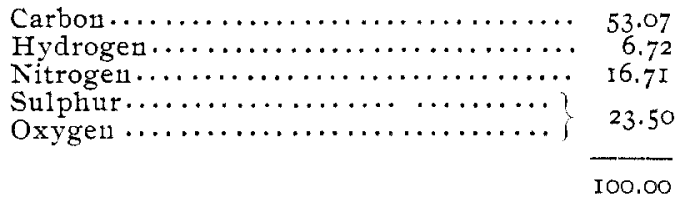

Leucosin is intimately associated with diastase.' Heated to $59^{\circ}$, solutions of this proteid become turbid, and at $58^{\circ}$ a flocculent coagulum occurs. Coagulation, however, is incomplete unless the solution is heated for some time and the temperature raised to about $70^{\circ}$. Saturation with sodium chloride or with magnesium sulphate partly precipitates leucosin.

3. A Protoproteose readily precipitated from aqueous solution by adding an equal weight of alcohol. No preparations of this body were obtained free from albumin. Its composition is nearly the same as that of leucosin, since preparations containing from ninety to fifty per cent. of it, together with from ten to fifty per cent. of leucosin, are not distinguishable by analysis.

4. A Protoproteose less readily precipitated by alcohol than the preceding, and of a different composition, as shown by the following figures:

Malt Protoproteose.

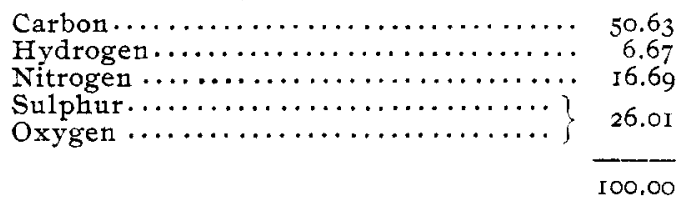

1 See papers on Diastase, Annual Reports of Conn. Agr. Expt. Station, 1894. pp. 202, 204, and I895, p. 238; also this JourNaL, 17,$587 ; 18,536$. 
That this is not an impure preparation of the preceding, is indicated by the fact that the amount of nitrogen is alike in both, while the carbon differs by two per cent. This difference would probably not be caused by non-proteid impurities. It is possible that the deuteroproteose next to be described, may not have been completely separated by the process employed.

5. A Deuteroproteose which could not be separated from nonproteid impurities.

6. A Heteroproteose in extremely small amount.

7. Bynin a proteid insoluble in water and saline solutions, but readily soluble in dilute alcohol. About I.25 per cent. of this proteid was obtained from the malt, having the following composition :

Bynin.

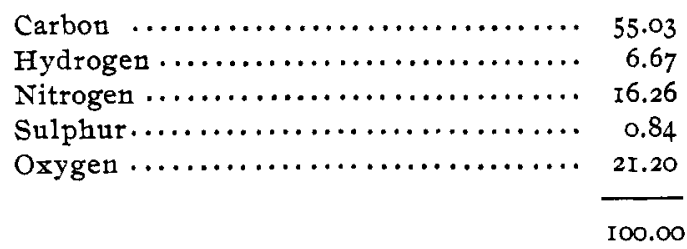

8. A proteid insoluble in water, in salt solution and in alcohol, amounting to 3.80 per cent. The composition and properties of this proteid we have been unable to determine.

Proportions of THE VARIOUS Proteids in MaLT.

Assuming twenty-one per cent. of the total nitrogen of the malt to exist in non-proteid bodies, and admitting the malt proteids to contain on the average 16.3 .per cent. of nitrogen, we have, in the malt investigated, a total of 7.84 per cent of proteids.

As already indicated, p. 555, proteid equal to three and eighttenth per cent. of the malt was insoluble in alcohol and in salt solution.

It was shown on page 553 that I. I per cent. of proteid was recovered from alcohol solution, and making allowance for loss, we may place the amount of alcohol-soluble proteid at I.25 per cent.

Subtracting the sum of the insoluble proteid and the alcohol soluble proteid from the total malt proteids, we have 2.79 per 
cent. for proteids soluble in salt solution, viz., globulin, albumin, and proteoses.

The amount of coagulable proteids was found to be 1.50 per cent., consisting of albumin and a part of the globulin. There remains then 1.29 per cent. for the uncoagulated globulin and the various proteoses. We have accordingly, in the malt used for these determinations, approximately :

Per cent.

Proteid, insoluble in salt solution and in alcohol $\ldots \ldots \ldots, 3.80$

Bynin, soluble in dilute alcohol................... I.25

Bynedestin, leucosin and proteoses \} Coagulable ........ I.5०

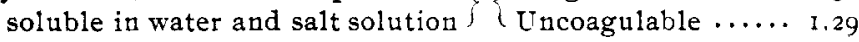

Total proteids............................... 7.84

The results of this study show : that, in germination, the proteids of barley undergo extensive changes without acquiring, or before acquiring the properties of proteoses ; that hordein disappears and an alcohol soluble proteid of entirely different composition takes its place; that edestin also disappears and a new globulin is formed, very different both in composition and properties. The albumin, on the other hand, appears to be unchanged in its characters, but its quantity is increased. It is to be noted also that hordein and edestin are both replaced by proteids much richer in carbon and poorer in nitrogen.

\section{NOTE.}

A Cheap Adjustable Electrolytic Stund.-Stands for electrolytic work, especially for efficient assaying of copper, should fulfill certain conditions.

All joints and connections, as far as possible, should be permanently soldered and very few switches used.

If many assays of the same kind are to be simultaneously conducted, each assay should be independent of its neighbor.

The stands or terminals, for holding the platinum cases or cylinders and spirals (which are the forms of electrodes generally used in large laboratories), should be capable of instant adjustment to suit a beaker of any height and size, or permit a block of wood to be placed under the beaker, since some chemists 